\title{
¿Es la antología un género? A propósito de las antologías sobre la traducción
}

\section{(Is an anthology a genre? About anthologies on translation)}

\author{
José ANTONIO SABIO PINILLA
} Universidad de Granada

Fecha de recepción: 8 de junio de 2011

Fecha de aceptación: 11 de julio de 2011

Resumen: Como parte de un proyecto de libro dedicado a las antologías sobre la traducción en el ámbito peninsular, en este trabajo se estudia la cuestión del género de la antología procurando abstraer sus rasgos definitorios. A continuación, se analizan las antologías de textos teóricos de la traducción, que son entendidas como obras históricas que proporcionan un conjunto de textos de la tradición occidental y de otras tradiciones menos conocidas con una finalidad fundamentalmente didáctica e investigadora Para ello, se tienen en cuenta los conceptos de reescritura y selección así como la concepción de la antología como libro. Para el análisis de todos estos aspectos se ejemplifica con las principales antologías existentes.

Palabras clave: Género. Antología. Textos teóricos. Traducción. Historia de la traducción.

Abstract: In the context of a forthcoming book on anthologies about translation theory published in Spain and Portugal, the present work studies the issue of the anthology as a genre in an attempt to isolate its defining characteristics. Following this, we analyze anthologies of texts on translation theory, which we take to be historical works offering a collection of texts-some drawn from the Western tradition and others that are less wellknown. Essentially, our objectives are both pedagogic and investigative. To achieve them, we draw on the concepts of rewriting and selection as well as that of the anthology as a book. To analyze all these aspects we draw on examples from the principle existing anthologies.

Key words: Genre. Anthology. Theoretical texts. Translation. History of translation

\section{LA CUESTIÓN DEL GÉNERO DE LA ANTOLOGÍA}

Parece existir cierto consenso sobre el hecho de que la antología es un género. Los ejemplos abundan: "Nos interesa el género de la antología como estructurador de la cultura" (Gallego Roca 1996: 42); "Como es normal en el género «antología», el compilador se limita a aportar documentos que no analiza ni tampoco presenta" (Lépinette 1997: 24); “el género de la antología sí tiene sentido dentro del conjunto de la cultura de un país" (Acín 2000: 158); "Para concluir, podemos afirmar que la antología constituye un género condicionado por las intenciones de las personas que 
participan en su elaboración (editor, antólogo, traductor)" (Pascual Garrido 2001: 169); "cuando se define la antología como género literario, es obvio que se está situándola a la par de los géneros mayores (lírica, épica o dramática)" (Ruiz Casanova 2007b: 54).

Tomando como punto de partida la última cita de Ruiz Casanova, un primer acercamiento a la cuestión del género nos lleva a considerar la antología literaria, especialmente la antología poética. El término antología (del griego ớvӨos "flor" y $\lambda \hat{\varepsilon} \gamma \omega$ "escoger") remite a la acción de reunir flores selectas (poesías) y se plasma de modo más gráfico en términos como florilegio ${ }^{1}$ o ramillete. A la metáfora primitiva de la flor y del tesoro que encierra, se suma la relativa a la memoria, que es inherente a la idea de conservación y transmisión de la riqueza de una cultura. En esta línea, la antología es "criba, principio de continuidad, creadora de cánones, instrumento de autoselección de una literatura" (Guillén [1985] 2005: 41), una especie de "depósito cultural" que preserva lo digno de ser recordado por lo que se ha comparado con otros métodos de compilación como los museos o las bibliotecas (Essmann y Frank 1991: 66-67).

Desde una perspectiva histórica, la antología puede entenderse como forma, en el sentido de "procedimiento tradicional de interrelación, ordenación o limitación de la escritura" (Guillén [1985] 2005: 159); una forma tradicional y convencional, común a numerosas culturas ${ }^{2}$, que permite el acceso a la literatura a través de textos escogidos. Esta forma, que Guillén incluye dentro de las "estructuras diacrónicas" ([1985] 2005: 371), ha actuado de "modelo mental" o "idea-tipo" ([1985] 2005: 144) y se documenta en Occidente al menos desde el siglo X con la Antología Palatina o griega. Su origen se remonta a la compilación de poesía griega (epigramas) para más tarde extenderse a otras compilaciones de verso y de prosa; por ello, no resulta extraño que la forma antología se haya contaminado del género de las obras que reúne y, particularmente en el caso de la antología poética, se haya convertido con el tiempo en "un género fuertemente codificado" (Gallego Roca 1996: 42).

El concepto moderno de antología surge en Europa a lo largo del siglo $X \mathrm{XX}^{3}$. Según Fraisse, la ampliación de su sentido se produce en

\footnotetext{
1 "En líneas generales puede decirse que los conceptos de antología y florilegio son muy similares, aunque en el caso de éste último se insiste más en su carácter selectivo, ya que reúne los frutos de la lectura" (Martínez 2001: 96).

2 Claudio Guillén constata la importancia de los florilegios no sólo en Occidente, desde Grecia, sino también en literaturas no europeas como la árabe, la japonesa y la china para sentenciar: "Un fenómeno de apariencia modesta como la antología se torna más significativo apenas averiguamos que se halla en cuantiosas culturas" ([1985] 2005: 41)

3 "[...] l'anthologie comme forme, saisie de manière plus restrictive, n'apparaît massivement et indiscutablement en Europe qu'au cours du XIX' siècle" (Fraisse 1997: 72).
} 
Francia con el paso de un modelo históricamente reconocido, la Antología Palatina o griega que recopila epigramas de diversos autores griegos, a una recopilación de poesías breves para posteriormente extenderse a toda recopilación de verso o de prosa. El cambio se consolida en el diccionario Larousse de 1866 y se consagra a finales del siglo XIX en La Grande Encyclopédie, que dota a ese sentido de un valor genérico y establece a su vez un paralelismo entre "anthologie", "morceaux chosis" y "éducation" (Fraisse 1997: 90-92). En España, el nacimiento de la antología moderna coincide con la proclamación oficial en el siglo XVII del "ingenio" como fundamento de una retórica nueva (Ly 2000: 38) y, al igual que en Francia, el término adquiere su actual significado a partir del siglo XIX, aunque la variedad de "formas antológicas" (cancionero, flor, florilegio, silva o, cuando tienen un fin didáctico, crestomatía, selecta o analecta) ha sido una constante en ambos países desde el siglo XVI para presentar textos poéticos selectos que den cuenta de la tradición literaria.

En resumen, la antología podría considerarse un género "si se entiende por género un architexto o texto de textos, como hace Gérard Genette (Introduction à l'architexte)", cuya estructura se ha ido definiendo históricamente y ha alcanzado un alto grado de prototipicidad, aunque debido a la variedad que ha adoptado podría igualmente situarse "en los límites difusos de forma y género" (Ruiz Casanova 2007b: 54).

\section{RASGOS DEFINITORIOS DE LA ANTOLOGÍA}

Ruiz Casanova ha subrayado la "aceptación tácita" que se ha producido de los rasgos definitorios de la antología, circunstancia que ha potenciado como principal característica de esta el que sea "producto de una elección" (2007a: 49) y, por consiguiente, se haya entendido como un trabajo basado en el gusto personal que obliga al antólogo a pedir disculpas para evitar posibles controversias 5 .

Un término común a todas las formas antológicas es colección, en el sentido que le da María Moliner (2007: 704): "Conjunto de cierto número de composiciones literarias del mismo género o con alguna característica que

\footnotetext{
4 Traducción de "formes anthologiques", usado por Fraisse en su libro sobre las antologías en Francia (1997).

5 "Los límites de la antología, a poco que en ellos se fije la mirada, se hacen borrosos porque lo que incluyen y excluyen indica tanto la imposibilidad de la selección perfecta como las preferencias subjetivas de quien la realiza. [...] Ante la posibilidad de que una antología pueda ser desmantelada desde sus mismas raíces, los autores de antologías se curan en salud y piden perdón por casi todo, [...] Pero la disculpa no es necesaria. Como cualquier percepción del mundanal ruido, las antologías ofrecen como totales fragmentos recompuestos coherentemente en pos de una finalidad" (Martínez 2001: 23).
} 
las une"6. A partir de este primer rasgo, que se adivina en el sintagma "forma colectiva intratextual" de la definición de Guillén ([1985] 2005: 375), la antología aglutina otros rasgos básicos:

a) ser una recopilación de textos que exige una selección;

b) la selección obedece a un doble eje de inclusión/exclusión;

c) los textos se organizan a partir de una serie de criterios definidos por el proyecto del antólogo;

d) la función principal es facilitar al lector textos ajenos que participan de lo fragmentario.

En suma, dos son los rasgos que priman a la hora de caracterizar la antología: el principio de selección, que implica un proceso previo de recopilación y otro simultáneo de inclusión/exclusión, y los criterios de organización que estructuren los textos en un conjunto nuevo.

A este respecto, son interesantes los comentarios de Fraisse (1997: 94-96). Para este autor, los rasgos contenidos en la idea de colección son compartidos por otras formas antológicas como la analecta, el centón, la crestomatía, el florilegio, el manual de lectura, el parnaso, el ramillete o la silva; ahora bien, lo que diferencia la antología de las restantes formas antológicas es el modo cómo se organizan los fragmentos. Es decir, no bastaría con poner el nombre de antología en el título de la obra para que esta adquiera el carácter antológico. En busca de una mayor especificidad, apunta algunas características que ayudan a perfilar lo expuesto anteriormente:

a) una intención del autor de la antología que se inscriba en el marco de una historia literaria y que dé cuenta de manera representativa de una crítica consciente de la literatura, de una literatura o de un movimiento literario;

b) que esa intención aparezca en el peritexto bajo la forma de un aparato crítico que no supere el $25 \%$ del texto total (un prólogo o un epílogo donde el antólogo explique su propuesta antológica, con notas biográficas y bibliográficas);

c) una ordenación de los textos;

d) un corpus que incluya una variedad de autores, como mínimo cinco.

Si no se dan estas condiciones, concluye Fraisse, no puede hablarse en sentido estricto de antología, sino solamente de forma antológica:

\footnotetext{
${ }^{6}$ Definición de antología: "Colección formada con trozos literarios seleccionados, de un autor o varios" (Moliner 2007: 207).
} 
En l'absence d'un regard organisateur, lisible dans l'appareil critique, préface ou postface, notices bio-bibliographiques, notes explicatives, sans mise en ordre immédiatement perceptible des textes retenus, il ne saurait y avoir anthologie véritable mais seulement forme anthologique. En radicalisant le propos, on pourrait estimer qu'il n'y a pas d'anthologie sans préface justifiant les partis adoptés par son auteur. (Fraisse 1997: 96)

Según ello, la antología debe incluir entre sus rasgos definitorios unos criterios de organización que estructuren los textos y un aparato explicativo que los integre en una visión de la historia literaria o cultural. Al proceso de recopilar y seleccionar, que recorre el género antología en sus diversas formas, ha de superponerse una elaboración que convierta la "forma antológica" en una obra capaz de ser entendida como "libro" y no como simple acumulación de textos (Ruiz Casanova, 2007a: 162). Ello implica poner en marcha una serie de estrategias que transformen los textos sueltos en un conjunto coherente, uno de los rasgos más difíciles de conseguir según Ruiz Casanova (2007b: 61). El antólogo, como responsable, deberá integrar los textos en un nuevo conjunto mediante un proceso de reconstrucción (manipulación) que dé una sensación de totalidad. Ese proceso parte de la selección de los textos y de los criterios que la guían, pasa por su ordenación (la cronológica es la más habitual, pero no la única) y se completa con un aparato paratextual (prólogo, notas, comentarios, bibliografía) que permita entender los textos en función del proyecto del antólogo. Los textos extraídos de sus contextos originales e incluidos al lado de otros textos en la obra antológica alcanzan un nuevo significado ("le texte reproduit dans l'anthologie ne signifie pas la même chose parce qu'il ne signifie pas de la même manière", Bravo 2000: 32), que necesita de todo el proceso anterior para completar la lectura ${ }^{7}$.

Esa lectura que propone la antología debe sustentarse en una determinada concepción de la historia literaria ("toda antología es, de suyo, el resultado de un concepto sobre una historia literaria", Reyes 1952: 112), rasgo definitorio que es propio de otras escrituras de la historia con un valor pedagógico, como manuales y libros panorámicos, que proporcionan una determinada visión de una tradición ${ }^{8}$. La manipulación del material

\footnotetext{
7 Las antologías, como los diccionarios y las enciclopedias, son obras "politextuales" que permiten una lectura discontinua, fragmentaria y selectiva: "si rien n'interdit d'en faire une lecture exhaustive et suivie, une anthologie a moins vocation à être lue qu'à être consultée" (Bravo 2000: 28).

${ }^{8}$ Continuando con la imagen que relaciona antología y museo como métodos de compilación, podría apuntarse la visión actual que da Eguidazu sobre lo que se entiende por museo hoy día y que encuentra paralelismo con la antología. Dice este autor respecto del nuevo Museo del Ejército ubicado en El Alcázar de Toledo: "Frente al patrón museístico de antaño como
} 
seleccionado encierra un objetivo (¿qué quiere conseguir el antólogo con su selección?) y obedece a unas condiciones ideológicas (¿qué base histórica tiene su escritura?): la antología surge así como un género de reescritura (Lefevere 1992a).

\section{LAS ANTOLOGÍAS DE TEXTOS SOBRE TEORÍA DE LA TRADUCCIÓN}

Dentro de la profusión de antologías destacan en nuestros días por su número y variedad las antologías de textos sobre teoría de la traducción, que pueden considerarse un auténtico fenómeno de moda en el ámbito europeo de los Estudios de Traducción (Lambert 1993: 91). Estas antologías reúnen y ponen al alcance del lector los textos más representativos de la reflexión traductora a lo largo de la historia (en un ámbito universal, en un ámbito lingüístico concreto o en una determinada tradición) y, según Brigitte Lépinette (1997: 24), "constituyen la base documental de la metatraductología histórica". Así, las antologías sobre la traducción representan uno de los géneros más cultivados en el marco de la historia de la traducción y su aparición responde a la doble necesidad de "cubrir un vacío y dotar a la disciplina de una perspectiva histórica" (Sabio Pinilla 2010: 9).

Siguiendo la clasificación ofrecida por Lépinette para las obras históricas (1997: 18-34), podemos dividir este tipo de antologías en dos grandes grupos en función del período temporal y los espacios culturales que abarcan" :

a) Generales: son aquellas antologías que recopilan textos sobre la traducción a lo largo de la historia, desde las primeras reflexiones hasta nuestros días. Pueden subdividirse en 1) antologías generales de carácter universal: aquellas que recogen diversas tradiciones traductológicas y ámbitos lingüísticos (Lefevere 1992b; Nergaard 1993; Vega 1994 [2004]; Lafarga 1996; López García 1996; Robinson 1997; Gallén et al. 2000); 2) antologías generales centradas en el estudio de una tradición (Horguelin 1981, para la francófona; Santoyo 1987; Catelli y Gargatagli 1998, ambas para la hispánica); y 3) antologías generales de ámbito nacional (Portugal: Pais 1997; Sabio/Fernández 1998; China: Cheung 2006b).

b) Parciales: aquellas antologías en las que se aplica una delimitación temporal de uno o, como máximo, dos siglos. Estas antologías se subdividen en 1) antologías parciales de carácter universal (Nergaard 1995);

almacén de objetos mejor o peor explicado —más bien lo segundo—, los modernos museos se conciben sobre todo como recorridos pedagógicos que ofrecen al visitante no sólo las piezas que integran sus colecciones, sino una explicación ordenada y detallada de las mismas en virtud de la cual el visitante pueda entenderlas y valorarlas tanto en sí mismas como en su contexto" (Eguidazu 2011: 34).

${ }^{9}$ Recogemos solamente aquellas antologías que se citan en este estudio. 
2) antologías parciales de una tradición (Steiner 1975, para la británica; Bacardí et al. 1998, para la del catalán; Dasilva 2006, para la gallega); y 3) antologías parciales de ámbito nacional (D'hulst 1990, siglos XVIII-XIX en Francia; García Garrosa y Lafarga, 2004 siglo XVIII; Cartagena 2009, siglos XIV y XV, ambas en España).

Todas estas antologías deben distinguirse de las antologías literarias estudiadas por Fraisse (1997), de las antologías poéticas (Gallego Roca 1996: 41-45; Ruiz Casanova 2007a) o de las antologías de traducciones (Pym 1998: 90-91; Frank 2000: 13-16). Sin embargo, comparten las características del género antología por lo que la primera parte de la definición clásica de Claudio Guillén ([1985] 2005: 375) es aplicable a todas: "La antología es una forma colectiva intratextual que supone la reescritura o reelaboración, por parte de un lector, de textos ya existentes mediante su inserción en conjuntos nuevos." Es decir, comparten los rasgos genéricos de ser una colección basada en la selección de textos que son producto de la lectura dirigida del antólogo (de un "superlector" según Guillén), que los reúne de acuerdo con unos criterios y siguiendo una ordenación que evite la acumulación de textos. Desde este punto de vista, las antologías sobre la traducción son un tipo de obra histórica que proporciona un conjunto de textos de la tradición occidental y de otras tradiciones menos conocidas con una finalidad fundamentalmente didáctica e investigadora.

En efecto, la mayoría de las antologías han sido elaboradas por profesores universitarios y han visto la luz en editoriales universitarias. La antología de Horguelin fue concebida como material didáctico para impartir la asignatura Historia de la Traducción a principios de los años setenta en la Escuela de Traducción de Montreal (1981: 13). La antología de Vega, que coincide con la transformación en España de las escuelas universitarias en facultades de Traducción e Interpretación durante el curso 1993-1994, pretende "que el traductor ya en activo o el que todavía se está formando sepa de dónde viene y adónde debe ir, para que no repita los mismos errores" (1994: 14). Todavía más acusado es el componente didáctico de la antología de Gallén et al., que está pensada "com um instrument de lectura i de consulta per acompanyar les explicacions de l'aula" (2000: 11). Por último, Cartagena recalca que el objetivo principal de su antología es "poner a disposición de los estudiantes y estudiosos de la traducción y de filología hispánica un sólido material de apoyo sobre el tema tratado" (2009: x).

\subsection{Reescritura y selección}

La antología implica la reescritura "de textos ya existentes en un conjunto nuevo". El concepto de reescritura, presente en la definición de Guillén y desarrollado por Lefevere (1992a), es clave para entender el 
fenómeno antológico. Al igual que la edición de textos, la traducción o la historia literaria, la antología es un tipo de escritura que sirve para reformular el pasado desde el presente; o, más concretamente, "desde los intereses del presente", como señala Talens (citado por Pozuelo Yvancos 2000: 40), porque "no se instituye para recuperar un pasado, sino para ayudar a constituir y justificar un presente". En el proceso de reunir, seleccionar y reeditar, la antología surge como un medio para reconstruir nuevos discursos o potenciar otros ya instituidos (Vidal Claramonte 1998: 55). Esa reformulación está marcada por unas condiciones ideológicas como sucede, por ejemplo, en las antologías de Lefevere (1992b), Catelli/Gargatagli (1998) y Cheung (2006b). Esta última considera que la reescritura nunca es inocente sino que "exists in a kind of interlocking relation with ideology and power" (2006b: 1). Su antología pretende dar a conocer en inglés las ideas de la traducción china en el ámbito internacional de los Estudios de Traducción; este objetivo implica la necesidad de adaptar conceptos pertenecientes a una tradición culturalmente alejada, para lo cual adopta el método de la "thick translation" de Appiah a fin de promover en la cultura de llegada una mayor comprensión y respeto por la cultura del Otro (2006b: 2-3).

De modo general, la reescritura pretende mostrar un pasado desconocido que genere conocimiento para el presente de la disciplina y ayude a entender los cruces entre diferentes tradiciones.

La selección es parte de la reescritura o, más bien, de la nueva escritura que propone el antólogo. El criterio principal invocado por los antólogos es el de la representatividad: los textos son representativos de las concepciones de la traducción en una determinada época (Horguelin 1981: 14), de la variada tipología que ha adoptado históricamente el pensamiento sobre la traducción y de su carácter de clásicos (Lafarga 1996: 15) o de la complejidad y diversidad de la teoría de la traducción (Robinson 1998: xx). La representatividad puede combinarse con el criterio del equilibrio de periodos, tendencias y traductores (Bacardí et al. 1998: 12-13) o puede obedecer a un criterio muy selectivo en consonancia con el objetivo didáctico (Gallén et al. 2000: 10) o, por el contrario, a criterios de amplitud y profundidad (Cheung 2006b: 14-15).

El número de textos varía en función de los objetivos de cada antología: las antologías generales de carácter universal oscilan entre los 10 textos de Nergaard y los 124 de Robinson; las generales de una tradición y de un ámbito nacional oscilan entre los 48 de Sabio/Fernández y los 250 de Cheung (incluido el segundo volumen, en preparación). En las antologías de carácter parcial de una tradición y de un ámbito nacional sorprende la diferencia entre los 19 textos de Steiner y los 210 de Dasilva. 
¿Cuál es el canon representado en las antologías de carácter universal? Los textos sagrados pertenecen a Cicerón, San Jerónimo, Lutero, Vives, Dryden, D'Alembert, Schleiermacher, Humboldt, Goethe, Mme de Staël, Benjamin y Ortega y Gasset. A estos nombres, que aparecen en casi todas las colecciones en diferentes traducciones, pueden añadirse los de Bruni, Cartagena, Dolet, Du Bellay, D'Ablancourt, Huet, Marmontel, Tytler o Pope. Es decir, la selección refleja tanto la lengua y tradición de origen de los antólogos como su formación.

\subsection{La antología como libro}

Tal vez sea el aspecto clave de una antología: su capacidad para ser entendida como libro con una estructura coherente. Esa estructura, que parte de la nueva escritura de los textos seleccionados, debe dotar de cohesión al conjunto y puede permitir diversas lecturas (o diversos "viajes", Cheung 2006b: 19) según los intereses de los lectores. Desde este punto de vista, las antologías de textos sobre teoría de la traducción deben considerarse un tipo de obra histórica capaz de soportar un análisis como libro.

\subsection{1. ¿Quiénes son los autores?}

Los antólogos son profesores de las áreas de Filología, de Literatura Comparada o de Traducción. Su escritura, basada en la reedición de textos, obedece a diferentes propósitos: proporcionar una serie de textos clásicos; llamar la atención sobre la importancia, complejidad y diversidad del estudio histórico con un fin docente e investigador; establecer relaciones entre diferentes sistemas literarios; dar a conocer una determinada tradición, un ámbito nacional o profundizar en el conocimiento de la traducción en una época concreta.

En el proceso de reactivar la memoria de los lectores seleccionando y rescatando del olvido textos mediante su reedición, el antólogo adopta diversas funciones: es autor ${ }^{10}$, es editor y, en las antologías plurilingües, es también traductor, labor en la que es ayudado por otros traductores y profesores.

\subsubsection{Los títulos}

Los títulos suelen ser largos, acotan el tiempo y el espacio cultural y orientan sobre los textos recogidos en la antología. Dentro de la diversidad de términos usados, "teoría" y su plural "teorías" son los preferidos por los

\footnotetext{
${ }^{10}$ Condición que suele ponerse en entredicho y que niega el carácter de libro a su obra como ha señalado Ruiz Casanova (2005: 7-45; 2007a: 86-87).
} 
antólogos. Sin embargo, pocos autores como Lafarga (1996) y Cheung (2006a, 2006b) explican la elección del concepto central. Tras descartar "reflexiones", "ideas" o "pensamiento", que no obstante prefiere a "teoría" o "teorías", Lafarga opta por "discurso de la traducción" porque muestra mejor la tipología textual que ha adoptado la reflexión a lo largo de la historia y el modo en que se ha traducido (1996: 14). Por su parte, Marta Cheung ha analizado en varias ocasiones el proceso que la condujo a elegir "discourse on Translation" en lugar de "theorie/theories on Translation" o "thought on Translation" señalando los problemas epistemológicos que conllevan (2006b: 1): el término "discourse", más abarcador, tendría una carga menos negativa para el lector y daría lugar a dos tipos de categorías de discurso directo e indirecto sobre la traducción que podrían aplicarse a toda la tradición china (2006a: 96-98).

\subsubsection{Los prólogos}

Junto al título hay un aparato paratextual que contribuye a perfilar la autoría del antólogo y a construir el libro como tal (Ruiz Casanova 2007a: 162). Forman parte de ese aparato los prólogos, la organización de los textos, las notas, los comentarios, la bibliografía, los apéndices y los índices, además de los agradecimientos y otros paratextos como mapas, ilustraciones o tablas.

En algunos casos hallamos varios textos preliminares: presentación e introducción (Vega); prefacio e introducción (Pais); prólogo y advertencia (Catelli/Gargatagli); palabras preliminares y presentación (Cartagena).

El prólogo suele informar de la selección y del procedimiento seguido por el antólogo. Ahí es donde hallamos una serie de tópicos a modo de justificación como, por ejemplo, los límites del espacio (Robinson, Gallén et alii), la eliminación de textos parecidos (Horguelin, Bacardí et al. o García Garrosa/Lafarga) o los lamentos por el carácter subjetivo de toda elección que no contenta a todos (López García 1996: 23). Es también el espacio donde se presenta la información historiográfica de la antología.

\subsubsection{Los textos}

Son textos muy variados que recogen reflexiones sobre la traducción principalmente de obras literarias. En su mayoría son prólogos de traductores, pero además encontramos introducciones, cartas, reseñas, entradas de diccionarios, fragmentos de obras gramaticales y de retórica, etcétera, como resultado de una práctica cultural que ha adquirido diferentes funciones y formas a lo largo de la historia. Por lo general, salvo los textos "clásicos", son textos dispersos y poco conocidos, que obedecen a una reflexión excéntrica y circunstancial. Este hecho plantea graves problemas de interpretación pues, como señaló D’hulst (1995: 19-23), los 
textos no son transparentes y su inclusión en el conjunto -muchas veces de modo fragmentario - no asegura un correcto entendimiento, es decir, el investigador debe plantearse la reconstrucción de las relaciones entre los textos y sus condiciones de funcionamiento histórico. Esta es una de las carencias más apuntadas (Lépinette 1997: 24).

\subsubsection{La ordenación}

El orden cronológico es el habitual aunque hay antologías que dan prioridad a otra ordenación:

a) por periodos mixtos de la historia literaria y traductora (Horguelin): para agrupar textos y autores en categorías representativas de la concepción de la traducción en una determinada época;

b) por formas discursivas (D'hulst y Sabio/Fernández): para dotar de dinamismo a la evolución de la reflexión traductora en Francia (17481847) y Portugal (ca. 1429-1818);

c) temática (Lefevere): para mostrar las causas ideológicas y poéticas que subyacen en los textos;

d) por bloques (Gallén et al.): para reconstruir mejor el contexto.

\subsubsection{La contextualización}

a) Presentación de las entradas

Las entradas incluyen siempre una información básica: el nombre del autor (a veces con fecha biográfica: Gallén et alii, Cheung), año (con excepción de López García) y texto (reproducido por lo general de modo fragmentario adaptando o respetando la ortografía original y en versión bilingüe en dos casos: Lafarga y Gallén et alii).

El título y la referencia a la edición pueden aparecer en el encabezamiento (Lafarga, Robinson, Cheung), en nota a pie de página (Santoyo, Sabio/Fernández), en nota al final del texto (Catelli/Gargatagli) o en un índice final (Horguelin, López García).

En los textos traducidos figura el nombre del traductor en la misma entrada (Robinson, Lafarga, Cheung) o al final del texto (Nergaard, López García).

En algunos casos los textos se numeran (Bacardí et alii, Catelli/Gargatagli o Dasilva).

b) Claves de lectura

Además de las entradas, las antologías deben proporcionar claves de lectura que orienten la comprensión de los textos.

Las antologías de Horguelin, Robinson, Catelli/Gargatagli y Cheung incluyen presentaciones, notas y comentarios. Las notas son más 
abundantes y exhaustivas en la de Cheung donde la necesidad de explicar conceptos y referencias es mucho mayor.

Las antologías de D'hulst, Sabio/Fernández y Gallén et alii incluyen varias introducciones para dotar de contexto a cada grupo de textos.

Un tipo especial son las antologías con estudio: Steiner analiza la teoría de la traducción en Gran Bretaña desde 1650-1800 para extraer los conceptos subyacentes de mímesis y originalidad que definen esa época; García Garrosa/Lafarga reconstruyen el discurso de la traducción del siglo XVIII español; Cartagena, por su parte, estudia la concepción de la teoría de la traducción en España durante los siglos XIV y XV.

Las antologías con introducciones generales proponen un marco histórico: puede incidir en la periodización (Santoyo), presentar un recorrido por la historia de la traducción (Nergaard), situar al lector en las claves historiográficas de la tradición occidental (Vega), mostrar algunas metáforas de la traducción en tradiciones menos conocidas (López García) o esbozar una primera aproximación histórica en Portugal como punto de partida para futuras investigaciones (Pais).

En el nivel más inferior se sitúan las antologías con una presentación general sin más explicación de los textos: Lefevere, Lafarga, Bacardí et alii, Dasilva.

c) Apéndices, índices y bibliografía

Pueden distinguirse dos tipos de antologías: las que incluyen solamente la bibliografía tras los textos (Bacardí et alii y Gallén et alii) y aquellas otras que presentan un corpus más elaborado (Robinson y Cheung). Ambos tipos se corresponden con el estilo de las editoriales donde aparecen: Eumo y St. Jerome. Especialmente complejo es el aparato de Cheung: biografía de los autores seleccionados y personajes mencionados; bibliografía de las obras citadas; bibliografía general (fuentes primarias y secundarias); índice de títulos; índice de nombres e índice general (conceptos).

Las antologías de Nergaard y Dasilva se aproximan al primer polo; pero la de Catelli/Gargatagli, que no incluye un apartado específico para la bibliografía como la de Santoyo, está más cerca del segundo.

Los datos biográficos de los autores seleccionados aparecen al final en Vega, Lafarga, López García y Sabio/Fernández.

La antología de Vega, que sitúa como la de Lafarga la bibliografía después de la introducción y antes de los textos, incluye al final una tabla sinóptica de la traducción desde el Renacimiento; esta tabla es adaptada por Pais en su antología. apéndice.

La antología de Cartagena es la única que incluye cuatro textos en 
El hecho de que la antología sea una forma libre, que obedece al criterio personal del antólogo, favorece su proliferación; así, a pesar de las semejanzas, no hay dos antologías iguales lo que permite encontrar una variedad de propuestas considerable. Cada antología presenta una estructuración propia del material seleccionado y por consiguiente deberá valorarse en función de la coherencia que mantenga con los principios adoptados por el antólogo.

\section{CONCLUSIONES}

Desde una perspectiva histórica, la antología es una forma tradicional que puede considerarse un género. Además de la idea de colección, para distinguirse de otras formas antológicas basadas en la mera recopilación, la antología necesita incorporar una serie de rasgos que integren los textos en el nuevo conjunto y doten de sentido al material recopilado: una selección con base en unos criterios, una ordenación que proponga una lectura de los textos, unas claves de interpretación y un aparato paratextual.

Las antologías sobre la traducción son un tipo de obra histórica que constituye un género dentro de los Estudios de Traducción. Los rasgos básicos de estas antologías son la reescritura y la selección. A su valor pedagógico ha de añadirse su función como herramienta de investigación y apoyo a la disciplina. En este sentido, estas obras nos recuerdan que la traducción es una actividad que hunde sus raíces en el pasado; proporcionan a estudiantes e investigadores un conjunto amplio de textos de la tradición occidental y de tradiciones más alejadas; muestran asimismo la íntima vinculación de la traducción con otras prácticas culturales y potencian el conocimiento de los contactos entre diferentes sistemas literarios.

Como obras históricas, las antologías sobre la traducción deben ser entendidas como libro cuyo autor es más que un recopilador de textos; para ello, los principios de su escritura deben ser coherentes con la estructuración del material seleccionado.

\section{REFERENCIAS BIBLIOGRÁFICAS}

Acín, Ramón. "El fenómeno antológico en Aragón: la prosa", en Geneviève Champeau y Nadine Ly (coord.), La phénomène anthologique dans le monde ibérique contemporain. Burdeos: Maison des Pays lbériques, 2000, pp. 157-170.

Bacardí, Monserrat; Fontcuberta, Joan y PARCERISAS, Francesc (eds.). Cent anys de traducció al català (1891-1990). Antologia. Vic: Eumo, 1998.

Bravo, Federico. "Les pratiques anthologiques. Pour une critique du fragment", en Geneviève Champeau y Nadine Ly (coord.), La 
phénomène anthologique dans le monde ibérique contemporain. Bordeaux: Maison des Pays Ibériques, 2000, pp. 19-34.

CARTAGENA, Nelson. La contribución de España a la teoría de la traducción. Introducción al estudio y antología de textos de los siglos XIV y XV. Madrid-Frankfurt: Iberoamericana-Vervuert (Medievalia Hispanica, 13), 2009.

Catelli, Nora y Gargatagli, Marietta. El tabaco que fumaba Plinio. Escenas de la traducción en España y América: relatos, leyes y reflexiones sobre los otros. Barcelona: Ediciones del Serbal, 1998.

ChAMPEAU, Geneviève y LY, Nadine (coord.). La phénomène anthologique dans le monde ibérique contemporain. Bordeaux: Maison des Pays Ibériques, 2000.

CHEUNG, Martha "From 'Theory' to 'Discourse'. The Making of a Translation Anthology", en Theo Hermans (ed.), Translating Others. Manchester: St. Jerome Publishing, vol. 1, 2006a, pp. 87-101.

, (ed.). An Anthology of Chinese Discourse on Translation. Volume 1: From Earliest Times to the Buddhist Project. Manchester: St. Jerome Publishing. [En preparación: An Anthology of Chinese Discourse on Translation: Volume 2: From the $13^{\text {th }}$ Century to the Beginning of the $20^{\text {th }}$ Century.] 2006b.

DASILVA, Xosé Manuel. Babel entre nós. Escolma de textos sobre a traducción en Galicia. Vigo: Universidade de Vigo, Servicio de Publicacións, 2003.

D'HULST, Lieven. Cent ans de théorie française de la traduction. De Batteux à Littré (1748-1847). Lille: P.U.L., 1990.

, "Pour une historiographie des théories de la traduction: questions de méthode", TTR, 8:1, 1995, pp. 13-33.

EGUIDAZU, Fernando. "Sobre el nuevo Museo del Ejército", en Revista de libros, número 172 (abril 2011), 2011, pp. 34-35.

ESSMANN, Helga y FRANK, Armin Paul. "Translation Anthologies: An Invitation to the Curious and a Case Study", Target, 3:1, 1991, pp. 65-90.

FRANK, Armin Paul. "Anthologies of Translation", en Mona Baker y Kirsten Malmkjær (eds.), Routledge Encyclopedia of Translation Studies. London /New York: Routledge, 2000, pp. 13-16.

FraISSE, Emmanuel. Les anthologies en France. Paris: PUF, 1997.

Gallego RocA, Miguel. Poesía importada. Traducción poética y renovación literaria en España (1909-1936). Universidad de Almería: Servicio de Publicaciones, 1996.

GallÉn, Enric; Llanas, Manuel; Ortín, Marcel; Pinyol i Torrens, Ramón y Quer, Pere. L'art de traduir. Reflexions sobre la traducció al llarg de la història. Vic: Eumo, 2000. 
García GaRRosA, Ma José y Lafarga, Francisco. El discurso sobre la traducción en la España del siglo XVIII. Estudio y antología. Kassel: Edition Reichenberger (Problemata Literaria 61), 2004.

GuILLÉN, Claudio. Entre lo uno y lo diverso. Introducción a la Literatura Comparada (Ayer y hoy). Barcelona: Tusquets Editores (Marginales, 229) [2 $2^{\mathrm{a}}$ ed.] 1985(2005).

Horguelin, Paul A. Anthologie de la manière de traduire. Domaine français. Montréal: Linguatech, 1981.

LAFARGA, Francisco (ed.). El discurso sobre la traducción en la historia. Antología bilingüe. Barcelona: EUB, 1996.

LAMBERT, José. "Anthologies et historiographie", Target, 5:1,1993, pp. 89-96.

LEFEVERE, André. Translation, Rewriting, and the Manipulation of Literary Fame. London / New York: Routledge, 1992a.

(ed.). Translation, History and Culture. A Sourcebook. London / New York: Routledge, 1992b.

LÉPINETTE, Brigitte. La historia de la traducción. Metodología. Apuntes bibliográficos. Valencia: Centro de Estudios sobre Comunicación Interlingüística e Intercultural (LynX. Documentos de trabajo 14), 1997.

LÓPEZ GARcíA, Dámaso (ed.). Teorías de la traducción. Antología de textos. Cuenca: Ediciones de la Universidad de Castilla-La Mancha, 1996.

LY, Nadine. "La pulsion anthologique. Anthologies de poésie espagnole: 1975-1996", en Geneviève Champeau y Nadine Ly (coord.), La phénomène anthologique dans le monde ibérique contemporain. Bordeaux: Maison des Pays lbériques, 2000, pp. 36-55.

MARRERo Henríquez, José Manuel. “El género de la disculpa”, en Eugenio Padorno y Germán Santana (eds.), La antología literaria. Las Palmas de G. C.- Fundación Mapfre Guanarteme: Universidad de Las Palmas de Gran Canaria, Servicio de Publicaciones, 2001, pp. 15-25.

MolineR, María. Diccionario del uso del español (a-i). Madrid: Editorial Gredos [3ª ed.], 2007.

NERgAARD, Siri (ed.). La teoria della traduzione nella storia. Milano: Strumenti Bompiani, 1993. (ed.). Teorie contemporanee della traduzione. Milano: Strumenti Bompiani, 1995.

PAIS, Carlos Castilho. Teoria diacrónica da tradução portuguesa. Antologia (Séc. XV-XX). Lisboa: Universidade Aberta, 1997.

PASCUAL Garrido, Mํㅡㄴ Luisa. Un hito en la poesía traducida en antologías: estudio descriptivo de La poesía inglesa (1945-1948) de María Manent. 2001. Tesis doctoral dirigida por Bernhard Dietz Guerrero. Córdoba: Universidad de Córdoba [en línea]. 
Pozuelo Yvancos, José Ma y Aradra Sánchez, Rosa Mạ. Teoría del canon y literatura española. Madrid: Cátedra (Crítica y Estudios Literarios).

PYM, Anthony (1998), Method in Translation History. Manchester: St. Jerome, 2000.

ReYEs, Alfonso. La experiencia literaria. Buenos Aires: Losada, 1952 ("Teoría de la antología" (1930), 112-116).

RoBInSON, Douglas (ed.). Western Translation Theory from Herodotus to Nietzsche. Manchester: St. Jerome, 1997.

Ruiz CASANOVA, José F. "La escritura del traductor", en José F. Ruiz Casanova, Henriette Partzsch y Florence Pennone, De poesía y traducción. Madrid: Biblioteca Nueva, 2005, pp. 7-45.

, Anthologos, poética de la antología poética. Madrid: Cátedra, 2007a.

(aut.). Antología Cátedra de Poesía de las Letras Hispánicas. Madrid: Cátedra (Letras Hispánicas) [6 ${ }^{\underline{a}}$ ed. aumentada y corregida], 2007b.

SABIO Pinilla, José Antonio y M. a Manuela Fernández SÁnChez. O discurso sobre a tradução em Portugal. O proveito, o ensino e a crítica. Antologia (c. 1429-1818). Lisboa: Edições Colibri, 1998.

SABIO PINILLA, José Antonio. "Las antologías sobre la traducción en España y Portugal: revisión crítica”, Sendebar, 21, 2010, pp. 7-20.

SANTOYO, Julio-César. Teoría y crítica de la traducción: Antología. Bellaterra: EUTI de la Universitat Autònoma de Barcelona, 1987.

STEINER, Thomas R. English Translation Theory 1650-1800. Assen: Van Gorcun, 1975.

TALENS, Jenaro. "El lugar de la Teoría de la literatura en la era del lenguaje electrónico", en Darío Villanueva (coord.), Curso de Teoría de la literatura. Madrid: Taurus, 1994, pp. 129-143.

VEGA, Miguel Ángel (ed.). Textos clásicos de teoría de la traducción. Madrid: Cátedra [2 $2^{\mathrm{a}}$ ed. aumentada, 2004].

Vidal Claramonte, M. a Carmen África. El futuro de la traducción: Últimas teorías, nuevas aplicaciones. Valencia: Institució Alfons el Magnánim, 1998. 